\title{
Biomechanical Analysis of the human femur bone during normal walking and standing up
}

\author{
A.E. Yousif ${ }^{1}$, M.Y. Aziz ${ }^{2}$ \\ ${ }^{I}$ (Professor, College of Engineering, Al-Nahrain University) \\ ${ }_{2}^{2}$ (Graduate Student, Medical Engineering Department, Al-Nahrain University)
}

\begin{abstract}
Biomechanics is a field that combines the disciplines of biology and engineering mechanics and utilizes the tools of physics, mathematics, and engineering to quantitatively describe the properties of biological materials. Finite element modeling has been widely used to describe the mechanical behavior of the long bones which have been created from CT (Computer Tomography) images In this study a three dimensional model of the human femur bone has been developed and the data associated with the hip contact forces for normal walking and standing up during one cycle has been employed on the femur bone in order to investigate behavior of the femur bone during these activities. The finite element results (stresses) are obtained and compared with previous studies. The behavior of the stresses that obtained in the present study is similar to those found in the literature. The results of the analysis are helpful for the orthopedic surgeon to understand the biomechanical behavior of the femur bone and also important for surgeon in femur surgeries and bone prosthesis.
\end{abstract}

Keywords: - Biomechanics, Finite Element Method, Femur bone, Gait Analysis

\section{INTRODUCTION}

Biomechanics is the application of mechanical principles on living organisms. By applying the laws and concepts of physics, biomechanical mechanisms and structures can be simulated and studied[1]. The gait cycle is defined as the time interval between two successive occurrences of one of the repetitive events of walking and is the basic measurement unit in gait analysis. The gait cycle begins when one foot comes in contact with the ground and ends when the same foot contacts the ground again[2]. During gait, important movements occur in all three planes - sagittal, frontal and transverse. The largest movements occur in the saggital plane. Saggital plane hip motion is essentially sinusoidal in walking. The loads on the hip joint during dynamic activities have been studied by several investigators. The force vector acting on the femoral head depends on the external forces acting on the limb and the internal forces primarily generated by muscle contraction. In general, the resultant force at the hip joint during walking reaches an initial peak in the early stance phase and a second peak in the late stance phase as described in [3,4]. Therefore in order to understand the mechanical behavior of the human femur bone , the Finite Element Method (FEM) is widely accepted as a power tool for biomechanics modeling. Irregular geometry, complex microstructure of biological tissues and loading situations are specific problems of the FEM in biomechanics and are still difficult to model [5]. FE model would be advantageous in complementing experimental works and in overcoming the inherent limitations associated with experimental studies which can provide only limited amount of information [6]. It is generally recognized that the employment of finite element analysis in the biomedical practice may potentially have a number of benefits such as offer additional evidence for clinical diagnosis of osteoporosis [7], help guide physical therapy [8], assist the development of more efficient/durable implants [9], and help improve the understanding of bone remodeling processes [10].

\section{A. Creating the model of the femur bone}

\section{METHODOLOGY}

For FE analysis of femur bone, firstly the three dimensional model of femur was developed. In the present study we have used an ideal femur bone model as presented in literature [11]. The model used represented an ideal human femur bone with age of 40 years old healthy individual whose weight is $75 \mathrm{Kg}$ which was reconstructed from CT (DICOM) images. The model was received as (.sat) file then it was imported to (ANSYS Workbench V12.1). then the model is divided into two parts, the upper part which includes the head and neck and the lower part which includes the body of the femur and the condyles, the process of creating two parts is to consider the upper part as cortical bone and the lower part as trabecular bone the process of dividing the femur bone is as follows:

a. After importing the three dimensional model in to the geometry window, a new plane has been created on the head of the femur the axes of the new plane has been rotated 90 in order to make the direction of the cut in $\mathrm{X}-\mathrm{Y}$ plane and the $\mathrm{Z}$ axes is pointed toward the longitudinal axes of the femur bone. 
b. The new plane surface has been shifted in $\mathrm{Z}$ direction distal to the head of the femur $(70 \mathrm{~mm})$ and shifted in $\mathrm{X}$ direction $(38 \mathrm{~mm})$ in order to prepare for the slicing process.

c. After that a freeze command in Ansys workbench (V12.1) has been applied on the femur bone then the slicing of the femur has been done by applying the slice command on the femur bone.

d. Now the femur bone is divided in to two parts upper part which includes the (Head of the femur and the neck) and the lower part which include (the body of the femur bone and the condyles of the femur).

e. The surface that separate the upper part form the lower part is considered as a contact region and this region affects the calculation of stresses in Ansys Workbench (V12.1) so a command in the program has been applied on the femur bone is (form new part) the process of applying this command is by selecting the two parts (upper part and lower part ) simultaneously and then a command of (creating new part) has been applied on the femur bone in order to connect the two parts together (glue) (the atoms the upper part overlap with the atoms of the lower part) .

f. Now the femur bone appears as a complete femur bone (one piece) without a contact between the upper and lower part but at the same time we are able to assign the material properties for the upper part different from the material properties of the lower part .

\section{B. Mesh Preparation}

Mesh is a very important step required for Finite Element Analysis of the femur model, an optimized mesh has been developed using model wizard in ANSYS Workbench, a proper setting and values have been executed in order to use smaller elements on proximities and curvatures for the model. The numbers of tetrahedral elements used for the femur model are 8603, while the number of nodes is 17148 as shown in Figure 1.

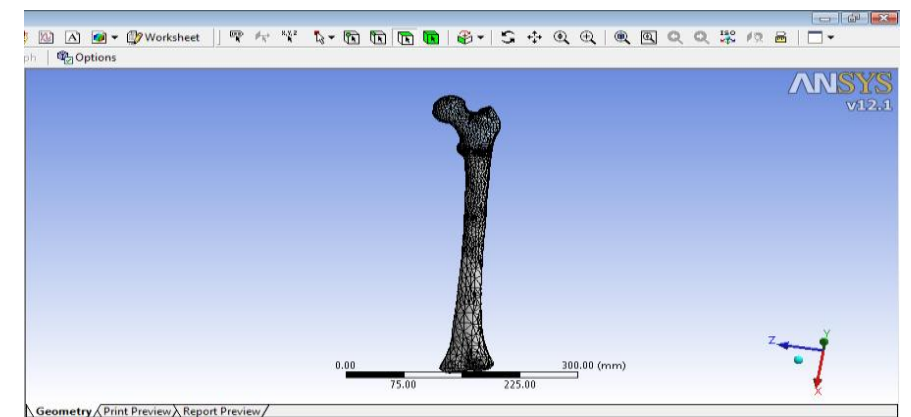

Figure 1 showing the femur model after making mesh process

\section{Assignment of material properties for the model}

One of the important parameters necessary for the stress analysis is the assignment of the material properties for the human femur model, we have assigned the material properties according to the values found in literature, the following section presents the major parameters assigned for our model:

a. Density: The density of the human femur bone has been chosen according to mathematical relationship

(1) that correlates the HU unit (Hounsfield Unit) with the density[12,13];

$\square \square \square \square 4.6410^{-4} \square H U \square 1$

Where: $\rho=$ Bone density $\left(\mathrm{g} / \mathrm{cm}^{\mathrm{a}}\right)$

HU $=$ Hounsfield Unit

We have taken HU as 800 for trabicular bone and HU 2200 for cortical bone as reported in literature [14].The range of $\mathrm{HU}$ for bone is from +700 for cancellous to +3000 for cortical[14]. After choosing the HU values, they were substituted to the above Eq. (1) to get the density for cortical and trabecular bones.

b. Modulus of Elasticity: Human bone is highly heterogeneous and nonlinear in nature, so it is difficult to assign material properties along each direction of bone model [1].

In the present study the behavior of the human femur bone has been assumed as orthotropic, homogeneous behavior, the values of the modulus of elasticity for the femur model have been found according to empirical relationships that correlates the density of the bone with the modulus of elasticity as reported in the literature $[13,15]$.

$$
\begin{aligned}
& E_{1 c}=E_{2 c}=2314 \rho^{1.57} \\
& \mathrm{E}_{a c}=2065 p^{\mathrm{a} .09} \\
& \mathrm{E}_{1 \mathrm{t}}=\mathrm{E}_{2 \mathrm{t}}=1157 \rho^{1.78} \\
& \mathrm{E}_{2 \mathrm{t}}=1904 \mathrm{p}^{1.64}
\end{aligned}
$$


Biomechanical Analysis of the human femur bone during normal walking and standing up

$V_{12}=0.4, V_{2 \mathrm{a}}=V_{\mathrm{a} 1}=0.25$

Where $\left(\mathrm{E}_{\mathrm{C}}, \mathrm{Et}\right)$ is the elastic modulus for the cortical and trabecular bone in $\mathrm{MPa},(\rho)$ density of the bone in $\left(\mathrm{g} / \mathrm{cm}^{\mathrm{a}}\right)$ and $(\mathrm{V})$ is the poisson ratio,1: radial, 2: circumferential and 3: longitudinal direction of the bone material.

The values of the densities for cortical and trabecular bone that get from Eq.(1) applied in Eq.(2), Eq.(3), Eq.(4) and Eq.(5) in order to calculate the Young's modulus for the cortical and trabecular bone .

The below table (I) illustrates the parameters that used to assign the material properties for the femur model.

TABLE I

Illustrate the parameters required for assignment of material properties for Finite Element Analysis

\begin{tabular}{|c|c|c|}
\hline Parameter & Cortical bone & Trabecular bone \\
\hline $\begin{array}{c}\text { Hounsfield Unit } \\
(\mathrm{HU})\end{array}$ & 2200 & 800 \\
\hline Density $\left(\mathrm{g} / \mathrm{cm}^{3}\right)$ & 2.0208 & 1.3712 \\
\hline $\begin{array}{c}\text { Modulus of } \\
\text { Elasticity(MPa) }\end{array}$ & $\mathrm{E}_{1}=6982.9$ & $\mathrm{E}_{1}=2029.4$ \\
\cline { 2 - 3 } & $\mathrm{E}_{2}=6982.9$ & $\mathrm{E}_{2}=2029.4$ \\
\cline { 2 - 3 } & $\mathrm{E}_{3}=18155$ & $\mathrm{E}_{3}=3195.3$ \\
\hline Poisson's Ratio & $\mathrm{v}_{12}=0.4$ & $\mathrm{v}_{12}=0.4$ \\
\cline { 2 - 3 } & $\mathrm{v}_{23}=0.25$ & $\mathrm{v}_{23}=0.25$ \\
\cline { 2 - 3 } & $\mathrm{v}_{31}=0.25$ & $\mathrm{v}_{31}=0.25$ \\
\hline \multirow{3}{*}{$\begin{array}{c}\text { Shear Modulus } \\
(\mathrm{GPa})[16]\end{array}$} & $\mathrm{G}_{12}=4.69$ & $\mathrm{G}_{12}=4.69$ \\
\cline { 2 - 3 } & $\mathrm{G}_{23}=5.61$ & $\mathrm{G}_{23}=5.61$ \\
\cline { 2 - 3 } & $\mathrm{G}_{31}=7.68$ & $\mathrm{G}_{31}=7.68$ \\
\hline
\end{tabular}

\section{Boundary Conditions}

An important step required for the FEA is the boundary condition for the femur bone model, a special procedure has been used to represent the boundary conditions for the femur model during the normal daily activities, the steps of the procedure are illustrated as followed:

a. A fixed boundary condition has been applied on the distal end of the femur and the hip contact force has been applied on the head of the femur in order to calculate the normal stresses for normal walking and standing up during this boundary condition.

b. A fixed boundary condition has been applied on the proximal end of the femur (Head region) and the hip contact force has been applied on the distal end of the femur in order to calculate the normal stresses during this boundary condition.

c. After calculating the stresses for the above two steps an averaging has been made for the results in order to calculate the average stresses for normal walking and standing up

\section{E. Loading Conditions}

The type of stress analysis used in the present study is the transient structural analysis (also called timehistory analysis). This type of analysis is used to determine the dynamic response of a structure under the action of any general time-dependent loads [17]. In Transient analysis, the load can be simulated with time dependent values, therefore in the present study we need to measure the hip contact force that applied on the head of the femur during a complete gait cycle for the activities included in my present study. Since 1980's, Bergmann and his research group have been pursuing the instrumented hip implants with telemetric data transmission [18-23]. Their collected gait data were recorded in HIP98 [24], and it was updated in 2001, these data were also updated in 2010 as reported in the literature [25] , these gait data which includes the hip contact force with the cycle duration have been used in my present study for a typical patient weight $(75 \mathrm{~kg})$ in order to calculate the stresses on the human femur bone . it is unique gait data base of the human hip contact force simultaneously measured in vivo. The activities included in my present study are illustrated in table (II).

TABLE II

Describe the activities included in the present study

\begin{tabular}{|c|c|}
\hline Activity & Description \\
\hline Normal & Walking at normal speed on level \\
Walking & ground, average speed: \\
& 3.9km/h(1.09m/s)
\end{tabular}


These hip contact forces have been plotted with respect to the gait cycle for normal walking and standing up as shown in Figure 2 and Figure 3.

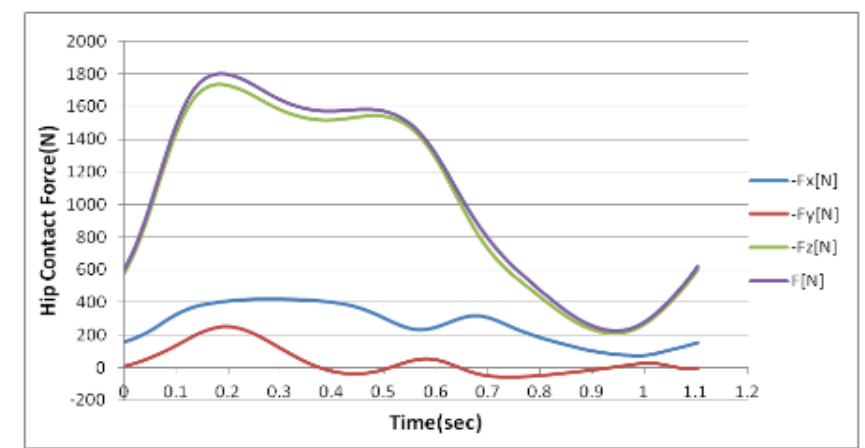

Figure 2 Hip contact force and its components during normal walking

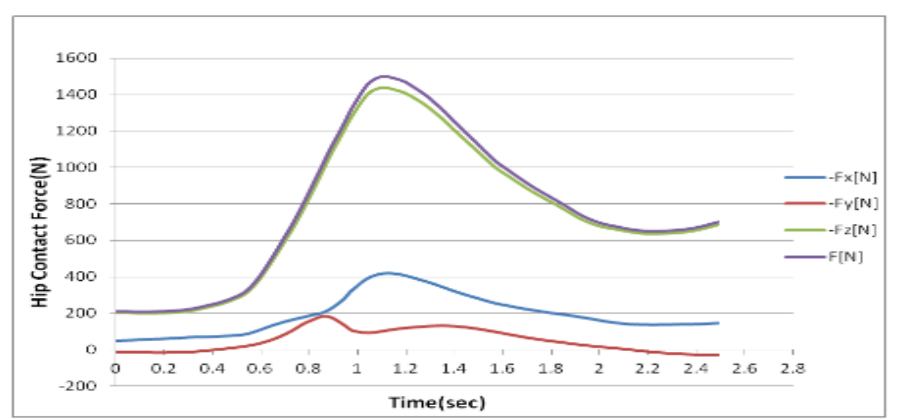

Figure 3 Hip contact force and its components during standing up

\section{RESULTS AND DISCUSSION}

The Normal stresses obtained from the stress analysis of the human femur bone during normal walking and standing up are shown in figure(4), Figure(5), Figure(6), Fig(7).the maximum normal stress during normal walking is $9.5 \mathrm{MPa}$ which is occurred on the neck of the femur while the maximum normal stress during standing up is $6.9 \mathrm{Mpa}$ which is also occurred on the neck of the femur. The results of stresses for normal walking and standing up have been plotted with cycle duration as shown in Figure (8) and Figure(10) and compared with the distribution of the peak stresses that is reported in the literature [26], the behavior of the stresses during normal walking is similar to the behavior of the stresses reported in literature [26] but there is a simple differences associated with the maximum peak stresses as shown in table (III) the differences are associated with following factors : (a) the geometry of the model, (b) the orientation and the application of the hip contact force this factor is important because the dominant effect in normal walking is hip contact force(major effect), (c) muscles forces which are not included in my present study, (d) the material properties used for the model and the behavior of the bone. The results of the stresses for standing up have been also compared with the stresses reported in literature [26], the behavior of the results are similar to the behavior of the results reported in literature [26] but there is also a difference associated with the maximum peak stress as shown in table (III) the difference associated with the following factors : (a) muscle forces this factor is important because the dominant effect in this activity is the muscle forces (Major effect) which are not included in my study (b) others factors associated with application, orientation of the hip contact force and the geometry of the model and also the behavior of the bone.

The obtained stresses are useful for tests on strength, fixation and friction of implants, for optimising their design and materials by computer simulation and also important for surgeon in femur surgeries and bone prosthesis.

Table (III)

showing the comparison of the peak stresses with those reported in previous study

\begin{tabular}{|c|c|c|}
\hline Activity & $\begin{array}{c}\text { Maximum Peak stress } \\
\text { in my study(MPa) }\end{array}$ & $\begin{array}{c}\text { Maximum Peak stress } \\
\text { as reported in } \\
\text { literature(MPa) [26] }\end{array}$ \\
\hline $\begin{array}{c}\text { Normal } \\
\text { Walking }\end{array}$ & 9.48 & 11.3 \\
\hline Standing Up & 6.9 & 10.3 \\
\hline
\end{tabular}


Biomechanical Analysis of the human femur bone during normal walking and standing up

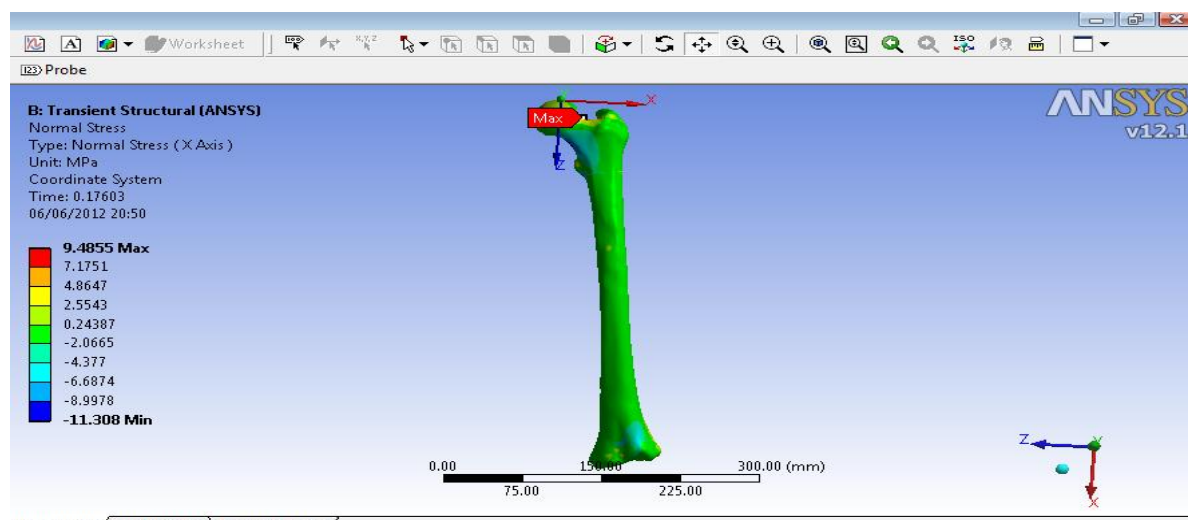

Figure 4 showing the distribution of the normal stresses during normal walking (Front View).

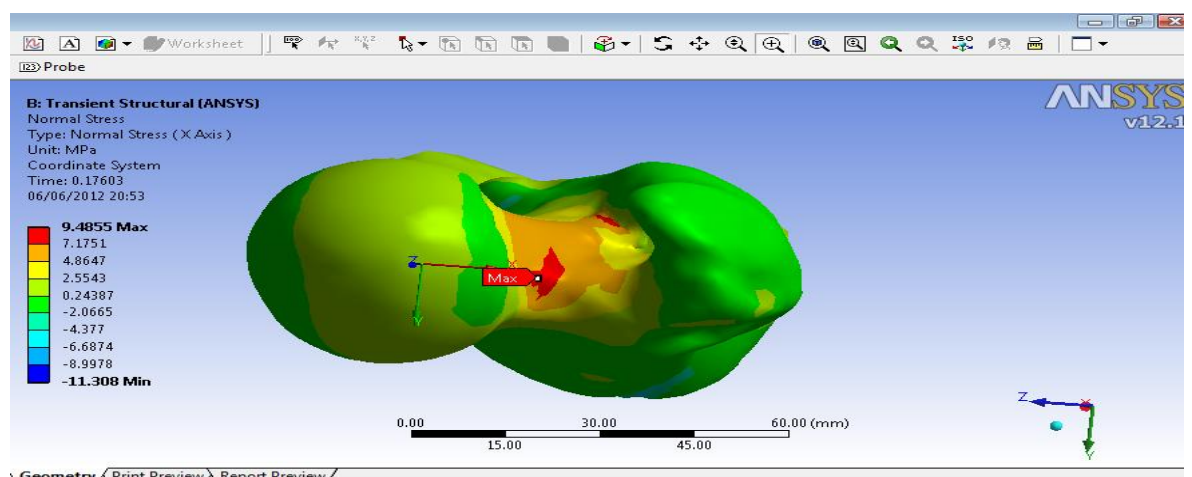

Figure 5 showing the distribution of the normal stresses during normal walking (Top View).

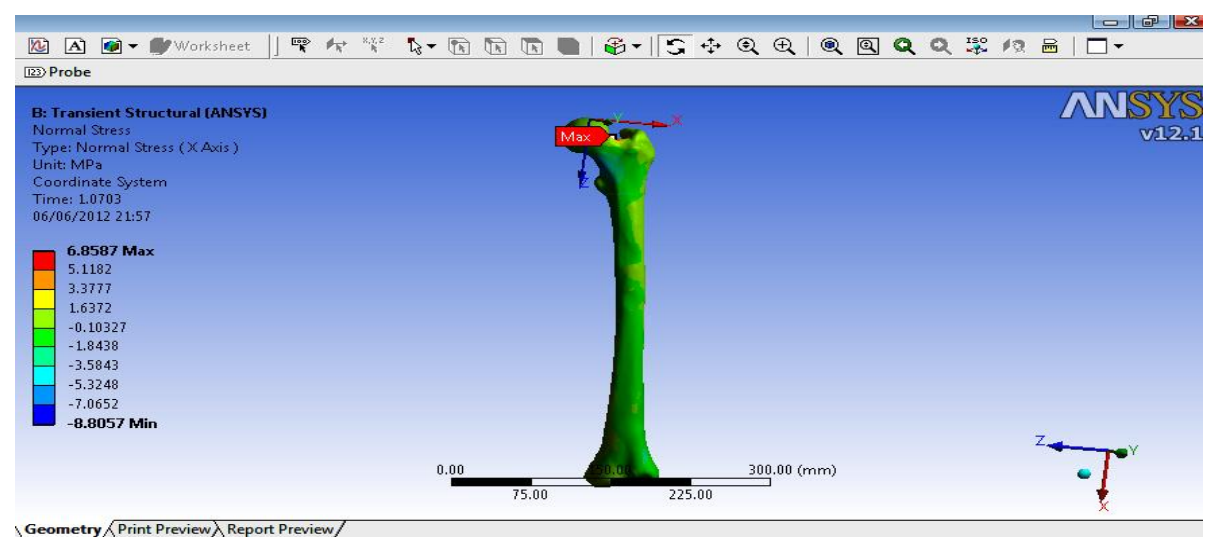

Figure 6 showing the distribution of normal stresses during standing up (Front View).

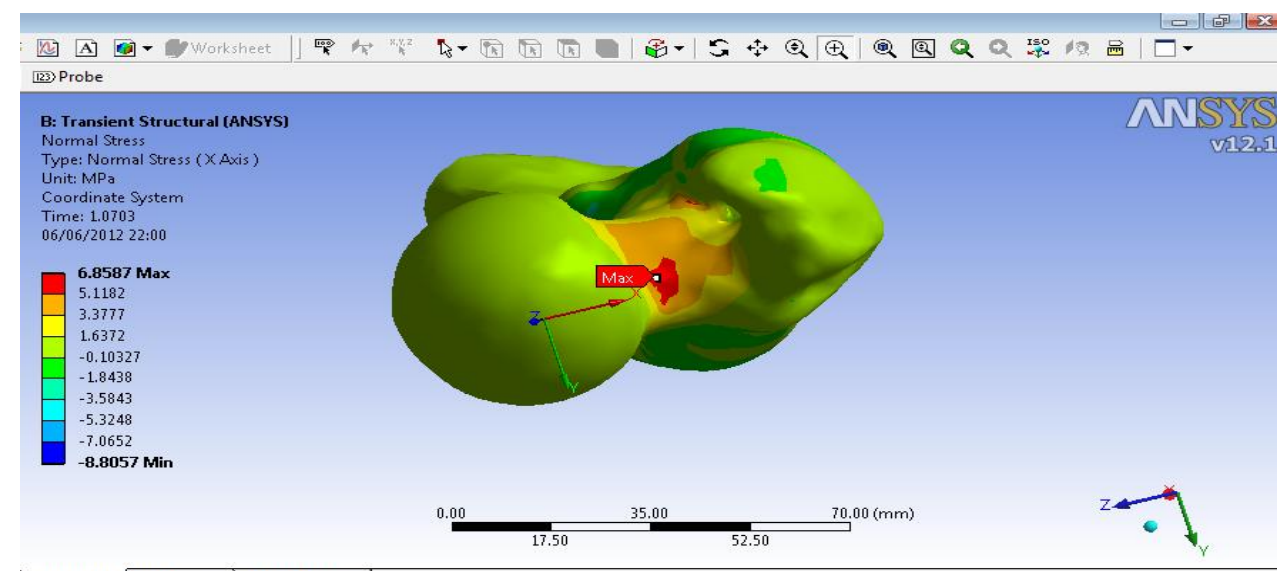

Figure 7 showing the distribution of the normal stresses during standing up (Top View) 


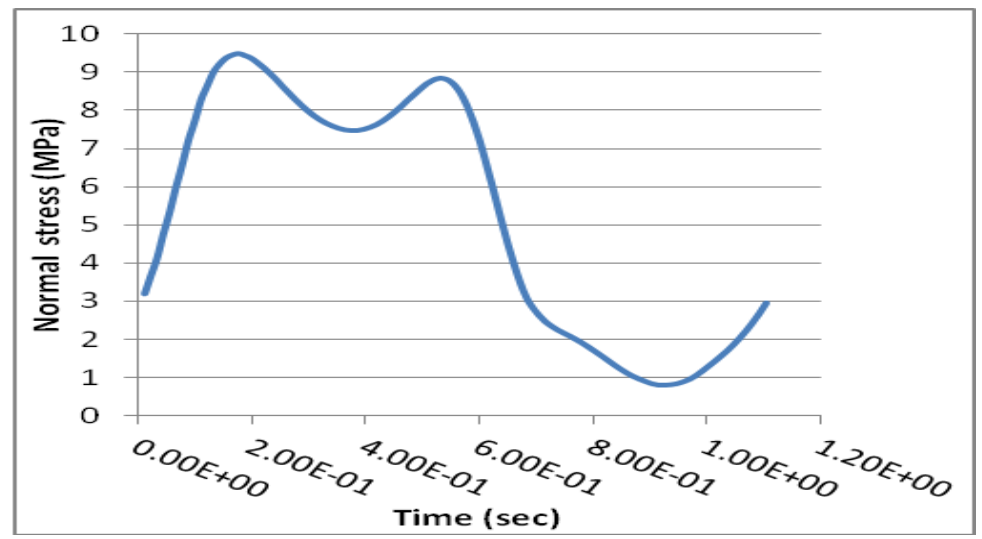

Figure 8 showing the distribution of the normal stress during normal walking.

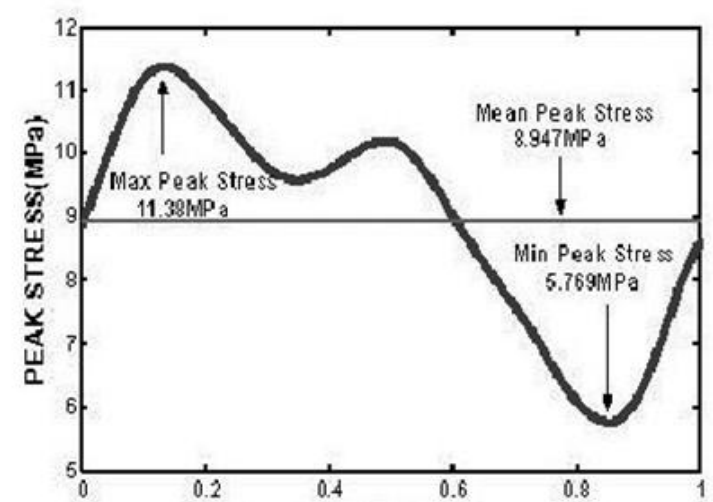

Figure 9 showing the distribution of the peak stress during normal walking as reported in literature [26]

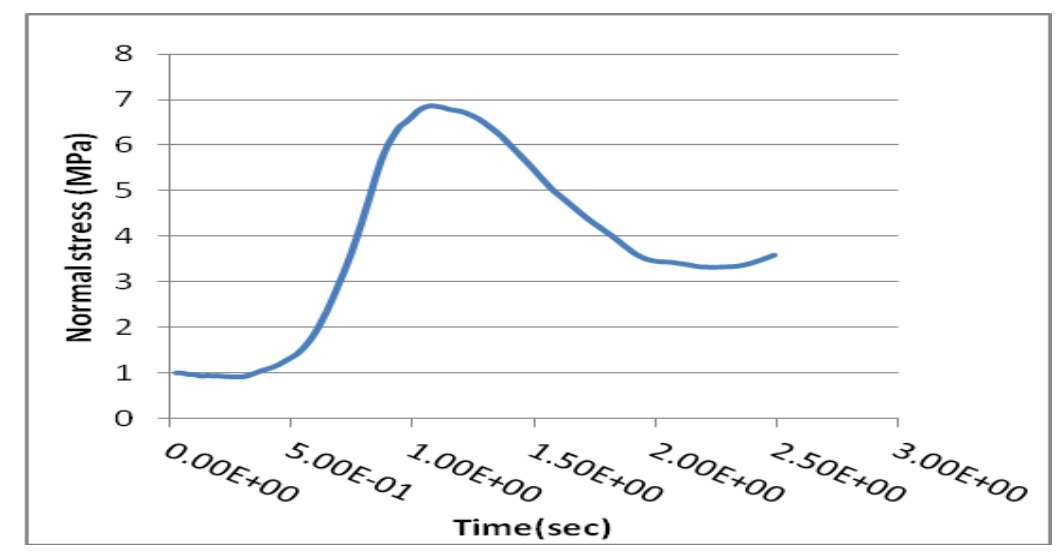

Fig.(10) showing the distribution of the normal stress during standing up

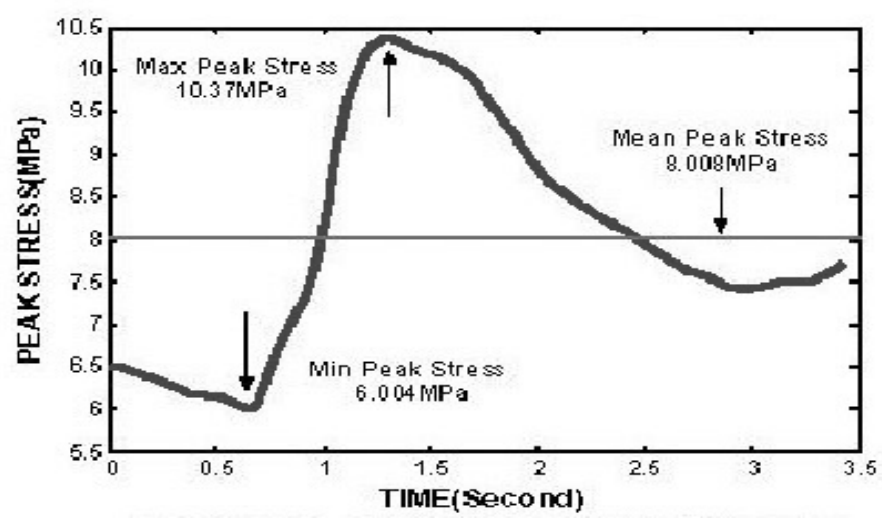

Fig.(3.11) showing the distribution of the peak stress during standing up as reported in literature [26]. 


\section{REFERENCES}

[1] RAJI NARELIYA , VEERENDRA KUMAR , "BIOMECHANICAL ANALYSIS OF HUMAN FEMUR BONE" , International Journal of Engineering Science and Technology (IJEST), Vol. 3 , No. 4 , 2011, 3090-3094.

[2] J. Perry, Gait analysis, normal and pathological function, 1 st ed., NJ: Slack, 1992, pp. 1-47, 111-129.

[3] J.P. Paul, "Comparison of EMG signals from leg muscles with the corresponding force actions calculated from walk path measurements ," Human Locomotor Eng, vol. 48A, 1971, pp. 6-26.

[4] T.P. Andriacchi , and D.E. Hurwitz , "Gait biomechanics and the evolution of total joint replacement ", Gait and Posture, vol. 5, 1997, pp. 256-264.

[5] Lengsfeld M. , Kaminsky J., Merz B. , Franke R.P., " Sensitivity of Femoral Strain Pattern Analyses to Resultant and Muscle Forces at the Hip Joint", Journal of Medical Engineering Physics, Vol. 18 , No. 1, 1996, pp. 70-78.

[6] Mc Namara B.P., Cristofolini 1. , Toni,A., Taylor D. ," Relationship Between Bone-Prosthesis Bonding and Load Transfer in Total Hip Reconstruction", Journal of Biomechanics, 30, No. 6, 1997, pp. 621-630.

[7] Hernandez C. And Keaveny T." A biomechanical perspective on bone quality", Bone , 39(6), 2006, 1173-1181.

[8] Frost H., "Why do bone strength and mass in aging adults become unresponsive to vigorous exercise? Insights of the utah paradigm “, Journal of Bone and Mineral Metabolism , 17(2), 1999, 90-97.

[9] Lee B.H. , Kim J. K. , Kim Y. D. , Choi K. , and Lee K. H. ," In vivo behavior and mechanical stability of surfacemodified titanium implants by plasma spray coating and chemical treatments “" Journal of Biomedical Materials Research Part A , 69(2), 2004, 279285.

[10] Doblare M. and Garcia J. M., "On the modelling bone tissue fracture and healing of the bone tissue", Acta Cient Venez, 54(1), 2003, 58-75.

[11] David W. Wagner, Kaan Divringi, Can Ozcan, M. Grujicic, B. Pandurangan, A. Grujicic, "Combined Musculoskeletal Dynamics/Structural Finite Element Analysis of Femur Physiological Loads during Walking”, Multidiscipline Modeling in Materials and Structures, Vol. 6(4), 2010, 417-43.

[12] Kourtis L.C. , Carter D.R. , Kesari H. , Beaupre G.S. ,” A new software tool (VA-BATTS) to calculate bending, axial, torsional and transverse shear stresses within bone cross section having inhomogeneous material properties", Computer Methods in Biomechanics and Biomedical Engineering, 11(5), 2008, pp.463-476.

[13] Baca V., Horak Z. , Mikulenka P. , Dzupa V," Comparison of an inhomogeneous orthotropic and isotropic material models used for FE analyses", Medical Engineering \& Physics, 30(7), 2008, pp.924-930.

[14] De Vos W. , Casselman J., Swennen GR. ", Cone-beam computerized tomography (CBCT) imaging of the oral and maxillofacial region: a systematic review of the literature", Int J Oral Maxillofac Surg. 38(6), 2009, PP.609-625.

[15] Peng L., Bai J., Zeng X. , Zhou Y.," Comparison of isotropic and orthotropic material property assignments on femoral finite element models under two loading conditions", Medical Engineering Physics, 28(3), 2006, pp.227-233.

[16] Franzoso G. , Zysset PK. , "Elastic anisotropy of human cortical bone secondary osteons measured by nanoindentation", J. Biomech. Eng. , 131(2), 2009.

[17] "ANSYS Workbench User Guide", ANSYS, Inc., 2009.

[18] Bergmann G. , Graichen F. , Siraky J. , Jendrzynski H., Rohlmann A. ," Multichannel strain gauge telemetry for orthopaedic implants", Journal of Biomechanics 21, 1988, 169-176.

[19] Graichen F, Bergmann G,." Four-channel telemetry system for in vivo measurement of hip joint forces", Journal of Biomedical Engineering 13, 1991, 370-374

[20] Bergmann G, Graichen F, Rohlmann A,. "Hip joint forces during walking and running, measured in two patients" , Journal of Biomechanics 26, 1993, 969-990.

[21] Bergmann G, Correa da Silva M, Neff G, Rohlmann A, Graichen F, "Evaluation of ischial weight bearing orthoses, based on in vivo hip joint force measurements". Clinical Biomechanics, 9, 1994, 225-234.

[22] Graichen F, Bergmann G, Rohlmann A ," Hip endoprosthesis for in vivo measurement of joint force and temperature", Journal of Biomechanics, 32, 1999, 1113-1117.

[23] Bergmann G, Deuretzbacher G, Heller M, Graichen F, Rohlmann A, Strauss J, Duda GN., "Hip contact forces and gait patterns from routine activities ", Journal of Biomechanics, 34, 2001, 859-871.

[24] Bergmann G, Graichen F and Rohlmann A. , "HIP98 (2001 Version)", Biomechanics Lab , Benjamin Franklin School of Medicine , Free University of Berlin, Gemany.

[25] Bergmann G, Graichen F, Rohlmann A, Bender A, Heinlein B, Duda GN, Heller MO, Morlock MM. , Realistic loads for testing hip implants", Biomed Mater eng., 20(2), 2010, 65-75.

[26] Xishi Wang, Tian Ying Wang, Fuchuan Jiang,Yixiang Duan , “The hip stress level analysis for human routine activities”, BIOMEDICAL ENGINEERING APPLICATIONS, BASIS \& COMMUNICATIONS , 17, 2005, 153-158. 